\title{
FAKTOR PENYEBAB PENYALAHGUNAAN NAPZA TERHADAP KEKAMBUHAN PASIEN PENGGUNA NAPZA DI RUMAH SAKIT PROVINSI SUMATERA SELATAN
}

\section{THE FACTORS OF USING DRUG ABUSE RELATED TO THE RECURRENCE OF PATIENTS AT MENTAL HOSPITAL IN PROVINCE SOUTH SUMATERA}

\author{
Trilia, Eva Rusmini
}

Sekolah Tinggi Ilmu Kesehatan Muhammadiyah Palembang, Sumatera Selatan, Indonesia (email penulis korespondensi :triliawm13@gmail.com)

\author{
Info Artikel: Diterima: 10 September $2019 \quad$ Revisi: 15 Oktober $2019 \quad$ Diterima: 09 November 2019
}

\begin{abstract}
ABSTRAK
Latar Belakang: Penyalahgunaan NAPZA saat ini sudah menjadi permaslahan dunia, terdapat sekitar 13,2 juta pengguna narkoba di dunia._Adapun faktor penyebab penyalahgunaan NAPZA yaitu faktor kepribadian, faktor lingkungan, faktor keluarga, dan faktor teman sebaya. Penelitian ini bertujuan untuk mengetahui hubungan faktor-fator penyebab penyalahgunaan NAPZA dengan kekambuhan pada pasien pengguna NAPZA di Rumah Sakit Ernaldi Bahar Provinsi Sumatera Selatan. Metode: Jenis penelitian ini adalah observasional analitik dengan desain potong lintang, jumlah sampel 33 pasien pengguna NAPZA, Analisis data menggunakan uji statistik chi-square.

Hasil: Hasil penelitian menunjukkan proporsi tertinggi pasien pengguna NAPZA di RS. Ernaldi Bahar Provinsi Sumatera Selatan adalah umur 25-44 tahun (dewasa) (57,6\%), pendidikan Menengah (Sma/smk) $(48,5 \%)$, pekerjaan wiraswasta $(51,5 \%)$, kepribadian introvert $(57,6 \%)$, lingkungan tidak sehat $(54,5 \%)$, keluarga harmonis $(54,5 \%)$, teman sebaya pecandu $(51,5 \%)$, dan kekambuhan $(60,6 \%)$. Hasil uji statistik menunjukkan 2 variabel yang berhubungan dengan kekambuhan yaitu faktor lingkungan $(p=0,003)$ dan faktor teman sebaya $(p=0,008)$, sedangkan 2 variabel lainnya tidak berhubungan dengan kekambuhan yaitu faktor kepribadian $(p=0,284)$ dan faktor keluarga $(p=0,172)$.

Kesimpulan: Diharapkan kepada pihak Rumah Sakit agar memperkuat program yang ada di pusat rehabilitasi, yang mampu membekali pasien untuk meningkatkan motivasi pasien penyalahguna NAPZA agar mereka tetap bertahan tanpa menggunakan NAPZA.
\end{abstract}

Kata Kunci : Penyalahgunaan NAPZA, Kekambuhan, NAPZA

\section{ABSTRACT}

Background: NAPZA (Narcotic, Pscychotropic, Additives) abuse has become world problem recently there are 13,2 million of narcotic users in the world. The causes of NAPZA abuse are personality factors, family and same age friendship.

Methods:This study was quantitative with Descriptive Analytic thorough Cross Sectional with total samples as much as 33 patients of NAPZA users this study was aimed to know the relationship between factors related with the cause of NAPZA abuse and the result there recurannce of NAPZA users patient in Policlinic at Ernadi Bahar Hospital in South Sumatera in 2015. The analysis of the data was using chi square staistic test.

Results:From the result of this study showed that the highest proportion of NAPZA users patient at RS. Ernaldi Bahar in South Sumatera was age 25-44 adult 57,6 \%, middle education level SMU $48,5 \%$, entrepeneur $51,5 \%$, introvert personalities $57,6 \%$, unhelathy enviroment $54,5 \%$, harmonic family 54,5\% same age friends with drug addiction $51,5 \%$ and reccurence $60,6 \%$. The result of statistic test showed 2 variables which related with recurennce were enviroment factors $(0,004) \alpha$ and same age friends with drugs $\alpha 0,008$, whereas other 2 variable $\alpha 0,172$.

Conclusion:It is hoped that health officilas at the hospital are able to strengthen their programms in rehabilition centre, which is ableto support all patients to elevate the motivation of NAPZA abuse users so they can survive without using NAPZA anymore.

Key words : NAPZA abuse, recurennce, NAPZA 


\section{PENDAHULUAN}

Penyalahgunaan narkotika dan obatobatan terlarang (Narkoba) saat ini sudah menjadi gaya hidup masyarakat. Pemakainya tidak lagi memandang dari status sosial. Dari orang dewasa sampai anak-anak, dari kaya sampai yang miskin sudah mengenal dan menggunakan narkotika dan obat-obatan terlarang. ${ }^{1}$ Pada akhir tahun 2003 diperkirakan terdapat 13,2 juta pengguna narkoba di dunia. Sekitar 22\% di antaranya hidup di negara maju, sedangkan sisanya berada di negara yang sedang berkembang atau sedang mengalami transisi, di Eropa Barat terdapat sekitar 1 juta sampai 1,4 juta pengguna narkoba $(9,41 \%)$, sedangkan di Eropa Timur dan Asia Tengah mencapai 2,3 sampai 4,1 juta $(24,18 \%)$. Di Asia Selatan dan Asia Tenggara jumlahnya jauh lebih banyak lagi yaitu mencapai 5,3 juta $(25,36 \%)$. Sementara di Asia Timur dan Pasifik 4 juta orang (17,66\%), Afrika Utara dan Timur Tengah 0,6 juta orang, Amerika Latin 1,3 juta, Amerika Utara 1,4 juta, Australia dan Selandia Baru hanya sekitar 298.000 orang. ${ }^{2}$ Data yang diperoleh dari Badan Narkotika Nasional (BNN) pengguna narkotika dan obat terlarang di Indonesia per tahun 2012 meningkat menjadi 4 juta orang atau meningkat 2 persen dari populasi dan meningkat dari riset sebelumnya yang sebesar 3,8 juta jiwa. ${ }^{3}$ Angka pecandu ini meningkat dikarenakan jumlah pencandu yang melakukan rehabilitasi sangat minim, dari 4 jutaan pencandu, hanya 18 ribu yang melakukan rehabilitasi. ${ }^{4}$

Hasil penelitian Badan Narkotika Nasional (BNN) bekerjasama dengan pusat kesehatan Universitas Indonesia pada tahun 2008 juga mencatat angka prevalensi nasional (penyalahgunaan narkoba) adalah $1,99 \%$ dari jumlah penduduk Indonesia (3,6 juta jiwa) dan pada tahun 2015 akan mengalami kenaikan menjadi $2,8 \%$ (5,1 juta jiwa). ${ }^{5}$ Hal tersebut menjadi salah satu penyebab Indonesia tidak lagi menjadi negara transit akan tetapi sudah menjadi negara pasar narkoba yang besar apalagi dengan harga yang tinggi (great market, great price), sehingga Indonesia semakin rawan menjadi surga bagi para sindikat narkoba. ${ }^{6}$

Sementara ini, Provinsi Sumatera Selatan untuk tahun 2014 total pengguna narkoba tercatat sebanyak 98.329 orang dari hasil penelitian Badan Narkotika Nasional (BNN) dan Universitas Indonesia (UI), bahkan tingkat perbandingan pengguna dengan jumlah peduduk Indonesia atau penduduk usia produktif (privalansi), Sumatera Selatan masuk peringkat ke-26 se-Indonesia. Jumlah itu dipastikan telah mengalami peningkatan seiring dengan maraknya peredaran narkoba di provinsi itu dalam beberapa tahun terakhir. Pencegahan dan Penyuluhan BNN Sumsel sosialisasi penyuluhan terhadap bahaya laten narkoba sudah dilakukan di beberapa sekolah dan di beberapa kabupaten/kota yang ada di Sumatera Selatan. ${ }^{7}$ Pada setiap kasus, ada penyebab yang khas mengapa seseorang menyalahgunakan NAPZA dan ketergantungan. Artinya, mengapa seseorang akhirnya terjebak dalam perilaku ini merupakan sesuatu yang unik dan tidak dapat disamakan begitu saja dengan kasus lainnya. Penyalahgunaan NAPZA (Narkotika, Psikotropika dan Zat Adiktif lainnya) adalah satu dari perilaku resiko tinggi tersebut. Penyalahgunaan NAPZA menimbulkan perasaan enak, nikmat, senang, bahagia, tenang dan nyaman, tetapketergantungan pada NAPZA dapat juga mengakibatkan dampak negatif dan berbahaya, baik secara fisik, psikologis, dan ${ }^{8}$

Upaya Promotif dan preventif ini mutlak harus dilakukan dalam pencegahan penyalahgunaan NAPZA. Di Indonesia dalam beberapa tahun terakhir ini masalah penyalahgunaan NAPZA telah menjadi suatu keadaan memprihatinkan sehingga menjadi masalah nasional. Korban penyalahgunaan NAPZA telah meluas sedemikian rupa sehingga telah melampaui batas-batas starata sosial, umur dan jenis kelamin ${ }^{9}$ Salah satu resolusi dari Single Convention On Narcotic Drug yang diadopsi oleh Konferensi Perserikatan Bangsa-Bangsa, menyatakan bahwa salah satu metode terapi yang paling efektif bagi pecandu zat adalah pengobatan di unit pelayanan kesehatan yang bersuasana bebas obat ${ }^{10}$ Metode yang dimaksud adalah dengan rehabilitasi sosial untuk memulihkan perilaku dan interaksi sosial bekas pecandu NAPZA ke tengah masyarakat, dapat ditempuh beberapa cara : keterampilan dan latihan kerja, pembinaan agama, narkotik anonymous, konseling, seminar-seminar kepribadian, dan kehidupan dalam komunitas bersama ${ }^{11}$

Salah satu faktor penyebab kekambuhan pada penyalahguna NAPZA adalah Kepribadian yang tidak tahan perubahan. ${ }^{12}$ mereka berpotensial kambuh dan cenderung tidak disiplin. Hal-hal yang sebelumnya sudah berusaha keras ia lakukan atau hindarkan, kembali lagi ia langgar dan tidak adanya dukungan atau bimbingan dari keluarga. 
Hingga saat ini ada kesalahan yang tak disadari yaitu mereka yang berobat lebih banyak berorientasi pada pengobatan fisik, sementara kurang dukungan penyembuhan yang berasal dari keluarga. ${ }^{12}$ Hasil prnrlitian yang dilakukan dari tahun 1997sd.1999 di empat rumah sakit terdapat 2 rumah sakit dengan kekambuhan pasien cukup besar dan meningkat dari tahun ke tahun, dengan proporsi rawat inap ulang sebesar $16,28 \%$ dan $12,14 \%{ }^{13}$ Dari hasil penelitian tersebut juga diperoleh bahwa pengaruh/bujukan teman merupakan awal seseorang menggunakan NAPZA dengan proporsi $81,3 \%$ dan selanjutnya dari teman itu pula kekambuhan terjadi dengan proporsi $58,36 \%{ }^{14}$

Berdasarkan studi pendahuluan dan data yang diperoleh dari Ruah sakit Ernaldi Bahar

\section{METODE}

Jenis penelitian ini adalah observasional analitik dengan desain potong lintang yang dilakukan dengan tujuan mendeskripsikan atau memberi gambaran terhadap suatu obyek penelitian yang diduga berhubungan antara variabel bebas dengan variabel tergantung. Peneltian ini dilakukan di Rumah Sakit Jiwa
Provinsi Sumatera Selatan jumlah pasien napza yang berkunjung berdasarkan tahun 2011 sebanyak 424 orang yang rata-rata setiap bulan nya 35 orang, 2012 sebanyak 305 orang yang rata-rata setiap bulannya 25 orang, 2013 sebanyak 364 orang yang rata-rata setiap bulannya 30 orang, 2014 sebanyak 327 orang yang rata-rata setiap bulan nya 36 orang (RS Ernaldi Bahar, 2015). Terkait dengan uraian di atas penulis berkeinginan melihat secara ilmiah faktor -faktor penyebab penyalahgunaan NAPZA pada klien pengguna NAPZA di ruang camar RS.Dr. Ernaldi Bahar Palembang tahun 2015. Oleh karena itu penelitian ini bertujuan untuk mengetahu faktor penyebab penyalagunaan NAPZA pada klien di Rumah Sakit Jiwa Ernaldi Bahar.

Ernaldi Bahar pada bulan Desember 2015. Jumlah sampel 33 pasien pengguna NAPZA yang merupakan total populasi. Data dikumpulkan dengan wawancara menggunakan kuesioner. Analisis data menggunakan uji statistik chisquare.

\section{HASIL}

Tabel 1. Distribusi Frekuensi Responden Berdasarkan Kepribadian, Lingkungan, Keluarga, Teman Sebaya, Kekambuhan Responden Poliklinik RSErnaldi Bahar Provensi Sumatera Selatan

\begin{tabular}{lcc}
\hline Karakteristik & Jumlah & \% \\
\hline Kepribadian & & \\
1. Ekstrovert & 14 & 42,4 \\
2. Introvert & 19 & 57,6 \\
Lingkungan & & \\
1. Sehat & 15 & 45,5 \\
2. Tidak sehat & 18 & 54,5 \\
Keluarga & & \\
1. Harmonis & 18 & 54,5 \\
2. Tidak Harmonis & 15 & 45,5 \\
Teman Sebaya & & 48,5 \\
1. Bukan Pecandu & 16 & 51,5 \\
2. Pecandu & 17 & 39,4 \\
Kekambuhan & & 60,6 \\
1. Tidak Kambuh & 13 & \\
2. Kambuh & 20 & \\
$\quad$ & & \\
\hline
\end{tabular}


Tabel 2. Faktor-faktor yang berhubungan dengan Kekambuhan Pada Pasien pengguna NAPZA di Poliklinik RS Ernaldi Bahar Provinsi Sumatera Selatan

\begin{tabular}{|c|c|c|c|c|c|c|c|}
\hline \multirow{3}{*}{ Variabel } & \multicolumn{4}{|c|}{ Kekambuhan } & \multirow{2}{*}{\multicolumn{2}{|c|}{ Total }} & \multirow{3}{*}{$p$-value } \\
\hline & \multicolumn{2}{|c|}{ Tidak kambuh } & \multicolumn{2}{|c|}{ Kambuh } & & & \\
\hline & $\mathrm{n}$ & $\%$ & $\mathrm{n}$ & $\%$ & $\mathrm{n}$ & $\%$ & \\
\hline \multicolumn{8}{|l|}{ Kepribadian } \\
\hline 1. Ekstrovert & 7 & 50,0 & 7 & 50,0 & 14 & 100 & $0.478^{*}$ \\
\hline 2. Introvert & 6 & 31,6 & 13 & 68,4 & 19 & 100 & \\
\hline \multicolumn{8}{|l|}{ Lingkungan } \\
\hline 1. Sehat & 10 & 66,7 & 5 & 33,3 & 15 & 100 & \multirow{2}{*}{$0.005^{*}$} \\
\hline 2. Tidak sehat & 3 & 16,7 & 15 & 83,3 & 18 & 100 & \\
\hline \multicolumn{8}{|l|}{ Keluarga } \\
\hline 1. Harmonis & 9 & 50,0 & 9 & 50,0 & 18 & 100 & \multirow{2}{*}{$0.284^{*}$} \\
\hline 2. Tidak harmonis & 4 & 26,7 & 11 & 73,3 & 15 & 100 & \\
\hline \multicolumn{8}{|l|}{ Teman Sebaya } \\
\hline 1. Bukan pecandu & 10 & 62,5 & 6 & 37,5 & 16 & 100 & \multirow{2}{*}{$0.013^{*}$} \\
\hline 2. Pecandu & 3 & 17,6 & 14 & 82,4 & 17 & 100 & \\
\hline
\end{tabular}

\section{PEMBAHASAN}

Hasil penelitian menunjukkan bahwa lingkungan berhubungan dengan kekambuhan pada pengguna NAPZA di Poliklinik Rumah Sakit Ernaldi Bahar Provinsi Sumatera Selatan. Pecandu narkoba akan kesulitan sembuh bila faktor lingkungannya tidak mendukung, menguatkan hasil penelitian ini, penelitian sebelumnya menunjukkan bahwa mantan pengguna narkoba pun akan sulit mengendalikan keinginannya mengonsumsi narkoba sampai kapanpun bila tidak didukung lingkungan yang baik. ${ }^{14,19}$

Lingkungan merupakan hal yang terpenting bagi seorang pecandu bisa sembuh, dimana lingkungan adalah tempat ia tinggal dan bergaul dengan orang lain yang bisa membawanya kearah yang mana baik atau burukkah, bila mereka berada di lingkungan orang yang banyak menggunakan napza maka besar kemungkinan mereka akan terpengaruh dan kembali menggunakan napza.

Variabel berikutnya yang memberikan kontribusi dalam kekambuhan pengguna Napza di Poliklinik Rumah Sakit Ernaldi Bahar Provinsi Sumatera Selatan adalah teman sebaya. Pengaruh buruk dari lingkungan pergaulan, khusus nya pengaruh dan tekanan dari kelompok teman sebaya sering menjadi sumber penyebab terjadinya penyalahgunaan NAPZA. Kelompok teman sebaya ini berperan sebagai media awal perkenalan dengan NAPZA. Penyalahgunaan
NAPZA pada kelompok teman sebaya merupakan prediktor yang kuat terhadap penyalahgunaan NAPZA.individu yang bergaul dengan kelompok penyalahguna NAPZA memiliki resiko tinggi untuk menjadi penyalahguna NAPZA ${ }^{16}$

Penelitian terdahulu mengemukakan bahwa faktor terbesar kekambuhan pasien NAPZA adalah faktor pertemanan (peer group). ${ }^{23}$ dari 293 pasien kambuh yang diteliti, 171 diantaranya kambuh karena pengaruh dan bujukan teman. Kondisi ini terjadi akibat pasien kembali bergaul dengan teman-temannya sesama pemakai NAPZA atau bandarnya. Teman merupakan $80 \%$ penyebab awal seseorang menggunakan NAPZA. Selanjutnya, dari teman pula suplai NAPZA diperoleh. ${ }^{24}$

Hasil penelitian terhadap para penyalahguna NAPZA yang kambuh, menyatakan bahwa ada hubungan yang signifikan antara kelompok teman sebaya dengan kekambuhan kembali para pecandu NAPZA. Mereka kembali kambuh karena ditawari oleh teman-temannya yang masih menggunakan NAPZA (mereka kembali bertemu dan bergaul). Kondisi pergaulan sosial dalam lingkungan yang seperti ini merupakan kondisi yang dapat menimbulkan kekambuhan. ${ }^{24}$

Hasil pada penelitian ini tidak menunjukkan hubungan yang signifikan antara kepribadian dengan kekambuhan pengguna NAPZA di Poliklinik Rumah Sakit Ernaldi Bahar 
Provinsi Sumatera Selatan, begitu pula hubungan keluarga dengan kekambuhan pengguna NAPZA .

Masalah penyalahgunaan narkotika, Psikotropika dan Zat Adiktif lainya atau istilah yang populer dikenal masyarakat sebagai NARKOBA merupakan masalah yang sangat kompleks, yang memerlukan upaya penanggulangan secara komprehensif dengan melibatkan kerja sama multidispliner, multisektor, dan peran serta masyarakat secara aktif yang dilaksanakan secara berkesinambungan, konsekuen dan konsisten. ${ }^{14}$

Upaya pencegahan seharusnya lebih diutamakan, hal ini mengingat dasar kegiatan dalam kesejahteraan masyarakat adalah mencegah itu lebih baik dari pada menyembuhkan. Selain itu juga mengingat bahwa dalam masalah penyalahgunaan dan ketergantungan terhadap NAPZA sangat sulit untuk dapat disembuhkan dengan cepat dan bahkan tidak ada jaminan untuk dapat sembuh total. ${ }^{13}$ Penelitian lain menyatakan bahwa tingkat kekambuhan pasien ketergantungan NAPZA mencapai $43,9 \%$, artinya hampir semua pasien ketergantungan NAPZA kembali menjadi pecandu setelah mereka dirawat untuk penyembuhan. ${ }^{16}$

Dalam upaya pencegahan penyalahgunaan NAPZA tidak cukup hanya diberikan pengetahuan tentang NAPZA saja, karena pengetahuan belum memadai untuk menghindari diri dari penyalahgunaan NAPZA tanpa didukung dengan kepribadian yang tangguh. ${ }^{16}$ Dengan mengetahui aspek yang paling berpengaruh pada penyalahguna NAPZA dapat dirumuskan dengan tepat cara menanganinya, agar pasien tidak kambuh kembali, karena sebagian besar penyalahguna NAPZA yang dirawat sering mengalami keadaan kambuh kembali dan dibutuhkan penanganan baru dengan biaya yang lebih mahal. ${ }^{17}$

Hasil penelitian sebelumnya menunjukkan salah satu faktor risiko terjadinya kekambuhan kembali adalah faktor dari diri sendiri dimana

\section{KESIMPULAN}

Lingkungan dan teman sebaya merupakan faktor yang signifikan menyebabkan kekambuhan pada pengguna NAPZA. Perlu diberikan penyuluhan pengetahuan tentang napza dan hal-hal yang dapat menyebabkan penyalahgunaan napza dan kekambuhan nya, agar bisa mengurangi
$78,8 \%$ pengguna memiliki kepribadian Ekstrovert. ${ }^{18}$ Sehingga dapat disimpulkan tidak terdapat hubungan antara kepribadian dengan kekambuhan pada pasien pengguna NAPZA di Poliklinik Rumah Sakit Ernaldi Bahar Provinsi Sumatera Selatan Tahun 2015 dikarenakan sebagian besar responden dari penelitian ini memiliki kepribadian responden introvert, dimana kepribadian introvert merupakan kepribadian yang kurang senang bergaul dengan lingkungan/ interaksi dengan orang banyak, sehinggga mempersulit dia untuk mengalami kekambuhan kembali.

Hasil penelitian menunjukkan bahwa keluarga tidak berhubungan dengan kekambuhan pada pengguna NAPZA di Poliklinik Rumah Sakit Ernaldi Bahar Provinsi Sumatera Selatan, hal ini dikarenakan keluarga bukan faktor utama penyebab mereka menggunakan napza, dan hasil penelitian menunjukkan bahwa sebagian besar responden adalah tergolong keluarga harmonis, ini bearti dalam proses kesembuhan pasien banyak mendapatkan dukungan dari pihak keluarga, sehingga memperkecil angka kekambuhan.

Keharmonisan keluarga yang buruk dapat menjadi faktor seseorang menjadi pengguna napza. ${ }^{20}$ Individu yang komunikasi keluarganya buruk berpeluang 5 kali lebih besar untuk menyalahgunakan napza. Risiko kambuh pada pasien pengguna narkoba sangat mungkin terjadi bila ia berada pada fase kecanduan. Beragam faktor pencetus kekambuhan juga berperan, salah satunya stigma negatif dari berbagai pihak termasuk keluarga.

Kekambuhan itu sangat tinggi terjadi pada mereka yang sudah kecanduan. Stigma negatif lainnya, seringkali berasal dari keluarga pasien misalnya melalui perkataan sebagai pemicu sehingga pasien akan kembali memakai narkoba. Proses rehabilitasi tidak serta merta membuat seseorang langsung pulih dari narkoba. ${ }^{20}$ Keluarga yang utuh lebih sedikit menghasilkan penyalahgunaan narkoba dibandingkan dengan keluarga yang berpisah (broken home). ${ }^{21,22}$

angka pecandu dan kekambuhan, dan juga dapat memperkuat program yang telah ada di pusat rehabilitasi, yang mampu membekali pasien untuk mengatasi trigger factor serta meningkatkan motivasi pasien penyalahguna NAPZA agar mereka tetap bertahan tanpa menggunakan NAPZA. 


\section{DAFTAR PUSTAKA}

1. Husni. 2004 . Penelitian penyalahgunaan dan peredaran gelap narkoba di Indonesia tahun 2003 dan 2004,. Diperoleh dari : http://eprints.undip.ac.id/

2. Djauzi, 2007. Waspadai peningkatan jumlah pengguna narkoba. Diperoleh dari : http://www.mitrainti.org/

3. Badan Narkotika Nasional, 2011. Pencegahanpenyalahgunaannarkobabagi remaja.diperoleh dari

https://bnnkgarut.wordpress.com

4. Holisah, 2014. 2014 Adalah Tahun Penyelamatan Pengguna Narkoba. Diperoleh dari : http://www.dakwatuna.com

5. BNN, (2010). Mahasiswa dan Bahaya Narkotika. Jakarta : Deputi Pencegahan Direktorat diseminasi Informasi.

6. Asni M, Rahma, Mukhsen S. 2013. Faktor yang Berhubungan dengan Penyalahgunaan Narkotika dan Bahan Adiktif (Narkoba) pada Remaja di SMA Kartika Wirabuana XX-1 Makassar Tahun 2013. Di peroleh dari http://repository.unhas.ac.id/bitstream/handle/

7. BeritAnda, 2015. Sumsel Ranking ke 26 Pengguna Narkoba Se Indonesia. Diperoleh dari: http://www.beritanda.com

8. Zulfa, 2014. http://eprints.ums.ac.id/.pdf

9. Penny A, 2013. .Narkotika1: Pengenalan dan Penyebab Psikologis.

10. Kurniawan, 2014. Napza. Diperoleh dari : http://kurniawan-ramsen.blogspot.com.

11. Fajrin Utami, 2014.Napza. http://www.scribd.com/doc/NAPZA-doc

12. Nasution, 2004. Memilih Lingkungan Bebas Narkoba. Jakarta : BNN.

13. Hawari D, 2006. Penyalahgunaan Dan Ketergantungan NAZA: Narkotika, alcohol dan zat adiktif. Jakarta: FKUI.

14. Lubis, S. 2012.Hubungan faktor internal dan faktor eksternal dengan kekambuhan kembali pasien penyalahguna NAPZA di Kabupaten
Deli Serdang. Diperoleh dari http://repository.usu.ac.id/bitstream

15. Notoatmodjo, S. 2010. Metodologi Penelitian Kesehatan. Jakarta : Rineka Cipta.

16. Afiatin, (2007).Bagaimana Cara Menghindarkan Diri Dari Penyalahgunaan Napza. Diperoleh dari : http://afiatin.staff.ugm.ac.id/.pdf

17. Dwiyanny, 2001. Aspek Yang Mempengaruhi Tingkat Kekambuhan Penggna Napza. Diperoleh dari: http://repository.usu.ac.id.pdf

18. Natalia, 2014. Faktor-faktor yang mempengaruhi penyalahgunaan Napzapada Pasien di Poliklinik Napza Rumah Sakit Jiwa Daerah Provinsi Sumatera Utara. Diperoleh dari : http://repository.usu.ac.id.pdf

19. Syarifah, 2014. Mantan Pecandu Narkoba Tidak Bisa Sembuh Selamanya. Diperoleh dari : http://health.liputan6.com

20. Diah, 2012. Pengaruh FaktorKeluarga Terhadap Kekambuhan Pasien Napza. Diperoleh dari : http://www.Journal.go.id.pdf

21. Hazelwood, R. R., \& Douglas, J. E. 1980. The Lust Murderer (pp. 18-22). FBI Law Enforcement Bulletin, US Department of Justice.

22. Gibson, E. J. 1969. Principles of perceptual learning and development. New York: Appleton-Century Crofts.

23. Hawari, Dadang. 2002. Dimensi Religi Dalam Praktek Psikiatri Dan Psikologi. Fakultas Kedokteran Universitas Indonesia: Jakarta.

24. Marlatt, G,A.; and Gordon, J.R. Determinants of relapse: Implications for the maintenance of behavior change. In: Davidson, P.O., and Davidson, S.M., eds. Behavioral Medicine: Changing Health Lifestyles. New York: Brunner/Mazel, 1980: 410-452. 